\title{
Correction to: Virtual visits for chronic neurologic disorders during COVID-19 pandemic
}

\author{
Irene Rosellini ${ }^{1}$ - Marika Vianello ${ }^{1} \cdot$ Anna Ghazaryan ${ }^{1} \cdot$ Silvia Vittoria Guidoni $^{1} \cdot$ Anna Palmieri $^{1} \cdot$ Federico Giopato $^{1}$. \\ Roberta Vitaliani ${ }^{1}$. Matteo Fuccaro ${ }^{1}$ - Alberto Terrin ${ }^{1}$ • Maria Teresa Rigoni ${ }^{1} \cdot$ Francesco Pietrobon $^{2}$. \\ Domenico Marco Bonifati ${ }^{1}$
}

Published online: 7 April 2021

(C) Fondazione Società Italiana di Neurologia 2021

Correction to: Neurological Sciences (2021)

https://doi.org/10.1007/s10072-021-05212-3

The original article contains an error in author name. The author "Vittoria Guidoni Silvia" should be replace with "Silvia Vittoria Guidoni" (Guidoni is the family name). The correct author name is presented above.

The original article has been corrected.

Publisher's note Springer Nature remains neutral with regard to jurisdictional claims in published maps and institutional affiliations.

The online version of the original article can be found at https://doi.org/ 10.1007/s10072-021-05212-3

Domenico Marco Bonifati

domenicomarco.bonifati@aulss2.veneto.it

1 Unit of Neurology, Department of Neuro-cardio-vascular, Ca'

Foncello Hospital, 31100 Treviso, Italy

2 Socio-health District South, AULSS 2 Treviso, Treviso, Italy 